\title{
The presence of tumour-infiltrating lymphocytes (TILs) and the ratios between different subsets serve as prognostic factors in advanced hypopharyngeal squamous cell carcinoma
}

\author{
Jie Wang ${ }^{1 \dagger}$, Shu Tian ${ }^{2 \dagger}$, Ji Sun $^{3}$, Jiahao Zhang ${ }^{3}$, Lan Lin ${ }^{3}$ and Chunyan $\mathrm{Hu}^{3 *}$ (D)
}

\begin{abstract}
Background: Cancer cells induce the infiltration of various immune cells that are located or distributed in different sites and play multiple roles, which have recently been proposed to predict clinical outcomes. We therefore studied the prognostic significance of the presence of tumour-infiltrating lymphocytes (TILs) and the ratios between different types of immune cells in hypopharyngeal squamous cell carcinoma (HPSCC).

Methods: We retrospectively analysed 132 consecutive patients diagnosed with advanced HPSCC in 2013-2017. Tumoural parenchyma was immunohistochemically counted manually for the number of CD8, CD4 and Foxp3 cells. The ratios of CD8/Foxp3 and CD8/CD4 ratios were calculated for each specimen and analyzed with respect to patient clinicopathological variables and prognosis.

Results: HPSCC patients with high levels of TILs showed evident correlations with well differentiated tumors $(P<0.05)$. Moreover, Foxp3+ TIL is also associated with overall staging group and T category $(P=0.048$ and $P=0.046$, respectively). Kaplan-Meier analysis showed that high CD8 and FoxP3 infiltration correlated with favourable overall survival (OS, $P=$ 0.019 and $P=0.001$ ), disease-free survival (DFS, $P=0.045$ and $P=0.028$ ) and distant metastasis-free survival (DMFS, $P=$ 0.034 and $P=0.009$ ), respectively, but only Foxp3 displayed prognostic significance for DMFS in multivariate analysis (MVA). In the lymphocyte ratio analysis, CD8/Foxp3 appeared to play a pivotal role, and patients with a high CD8/Foxp3 ratio had a superior 3-year DFS and DMFS compared with those a low CD8/Foxp3 ratio in both univariate analysis (UVA) and MVA ( $P=0.015$ and $P=0.011)$. A high CD8/CD4 ratio was associated with better DFS and local relapse-free survival (LRFS) in UVA, and was an independent prognostic factor for improved LRFS in MVA $(P=0.040)$.
\end{abstract}

\footnotetext{
* Correspondence: huchy2003@163.com

${ }^{\dagger}$ Jie Wang and Shu Tian contributed equally to this work.

${ }^{3}$ Department of Pathology, Eye \& ENT Hospital, Fudan University, 2600 jiangyue Road, Shanghai 201112, China

Full list of author information is available at the end of the article
}

(c) The Author(s). 2020 Open Access This article is licensed under a Creative Commons Attribution 4.0 International License, which permits use, sharing, adaptation, distribution and reproduction in any medium or format, as long as you give appropriate credit to the original author(s) and the source, provide a link to the Creative Commons licence, and indicate if changes were made. The images or other third party material in this article are included in the article's Creative Commons licence, unless indicated otherwise in a credit line to the material. If material is not included in the article's Creative Commons licence and your intended use is not permitted by statutory regulation or exceeds the permitted use, you will need to obtain permission directly from the copyright holder. To view a copy of this licence, visit http://creativecommons.org/licenses/by/4.0/ The Creative Commons Public Domain Dedication waiver (http://creativecommons.org/publicdomain/zero/1.0/) applies to the data made available in this article, unless otherwise stated in a credit line to the data. 
(Continued from previous page)

Conclusion: Although high TILs levels were determined to be prognostically significant in advanced HPSCC, the ratios of these subsets may be more informative. Particularly, a higher ratio of CD8/Foxp3 accurately predicts prognosis for improved DFS and DMFS, and an increased CD8/CD4 ratio is an independent predictor for favourable LRFS.

Keywords: Tumour-infiltrating lymphocytes, CD8/Foxp3 ratio, CD8/CD4 ratio, Immunohistochemistry, Advanced hypopharyngeal squamous cell carcinoma

\section{Background}

Hypopharyngeal squamous cell carcinoma (HPSCC) is a highly malignant type of head and neck cancer, which is the eighth most common cancer worldwide [1]. Although its incidence is comparatively low, HPSCC is usually diagnosed at an advanced stage due to unapparent early symptoms [2] . Although there are many treatments, such as surgery, concurrent chemoradiation therapy (CCRT) and radiation therapy, the five-year survival rate is less than $35 \%[3,4]$. Given the difficulty of diagnosing HPSCC at an early stage as well as its severe prognosis, new approaches concerning prognostic evaluation and treatment alternatives are necessary. It is urgent to find novel biological factors that accurately predict clinical outcomes for HPSCC patients.

In recent years, it has been increasingly recognized that the immune microenvironment is the "battlefield" between tumour progression and the immune system defence. Immune surveillance and immune escape provide a dynamic balance, inhibiting tumour progression by recognizing and killing tumour cells, and weakening the antitumour activity of immune cells by expressing inhibitory molecules and secreting cytokines [5]. Tumour-infiltrating lymphocytes (TILs), which are heterogeneous lymphocyte population mainly composed of $\mathrm{T}$ lymphocytes, are important in the tumour immune microenvironment; they were first proposed in 1986 and have been proven to be an independent prognostic biomarker in various tumours [6-9]. Growing evidence indicates that TILs consist of numerous antitumour effector or regulatory $\mathrm{T}$ cells (Tregs) and are key players in the host's immune response to tumour. Thus, evaluating the functions of different TIL subsets may provide a better understanding of tumour progression and effective antitumour strategies. In fact, the most consistently beneficial TILs seem to be CD8+ TILs, which are regarded as cytotoxic T lymphocytes (CTLs), and specifically recognize and destroy target cells [10]. These cells have been reported to be the major effector cell for tumour elimination by recognizing tumourderived antigenic epitopes [11]. In contrast, Foxp3+ TILs have been classified as Tregs, and may actually contribute to suppressing antitumour immune responses [12]. In most studies, Tregs are generally considered to play a crucial role in the process of immune escape, helping tumour cells avoid immunological surveillance. However, the prognostic significance of Foxp3+ TILs remains controversial. For instance,
Foxp3+ TILs were reported to be linked to favourable clinical outcomes in non-small cell lung cancer (NSCLC) and sinonasal squamous cell carcinoma [13, 14], but others reported that Foxp3+ TILs were correlated with to worse prognosis $[15,16]$. Furthermore, CD4+ TILs are derived from $\mathrm{T}$ cells mediated by IL-2, which include a $\mathrm{T}$ helper cell population and Tregs. In terms of antitumour immunity, $\mathrm{T}$ helper cell activation is effective and plays an important role in inducing or motivating CTLs, whereas CD4+ Tregs suppress effector $\mathrm{T}$ lymphocytes $[17,18]$. However, whether these pro-tumour effects outweigh antitumour effects or are equal in a particular tumour is debatable. This could explain why the benefits of CD4+ T cell infiltration on the prognosis of different tumours are somewhat inconsistent. From the above, it is evident that TILs may act as a double-edged sword, and the relations between the different types of immune cells have not been thoroughly examined. More recently, the hypothesis that lymphocyte ratios could have more prognostic significance has gained much attention. Emerging evidence has shown that higher ratios of $\mathrm{CD} 8+$ / Foxp3+ and CD8/CD4 are more sensitive indicators of prognosis and for monitoring immune function, even serving as biomarkers to predict tumour relapse and responses to treatment [13, 19-21]. A study by Sideras et al. examined the fresh metastatic tissues of 47 patients with colorectal cancer liver metastases and found a high CD8+/Foxp3+ ratio was an independent predictor of survival [22]. Specifically, the ratios of these subsets may provide a more comprehensive view of what occurs in the tumour microenvironment and which $\mathrm{T}$ cell subtype dominates or is likely to overshadow the functions of other T-cells. Previous works have demonstrated that high CD8 and Foxp3 expression contributed to better overall survival (OS) and diseasefree survival (DFS) in HPSCC, yet the correlations of CD8/Foxp3 and CD8/CD4 wiht clinical outcomes remain unclear.

Based on the consideration that the quantitative ratios are probably more important in the tumour immune microenvironment, this study focuses on the prognostic significance of TILs and the relations of the CD8/Foxp3 and CD8/ CD4 ratios with clinical outcomes and further seeks to determine more reliable biomarkers in a relatively larger advanced HPSCC cohort, which may appropriately select high-risk patients eligible for more aggressive therapeutic agents. 


\section{Methods}

\section{Specimens and0020patients}

The present study enrolled 132 patients with HPSCC from 2013 to 2017, who underwent surgical treatment at the Eye and ENT Hospital of Fudan University, Shanghai, China. None of the patients received neoadjuvant chemotherapy or other therapies. All HPSCC specimens were fixed in 10\% formalin and embedded in paraffin for histopathological analysis and immunohistochemistry. Haematoxylin-eosin (HE) staining of the sections was in an automated stainer/coverslipper workstation (HistoCore SPECTRA ST, Leica, Wetzlar, Germany). Complete clinical data were collected and all patients gave written informed consent before surgery. The Institutional Review Committee of the Eye and ENT Hospital granted ethical approval.

\section{Immunohistochemical (IHC) staining and evaluation}

IHC staining was performed in automated immunostainer (Ventana Medical System, USA) using the following antibodies: anti-CD8 (SP16 Gene Tech, Shanghai, China, ready to use), anti-CD4 (EP204 Gene Tech, Shanghai, China, ready to use) and anti-Foxp3 (rabbit mAb, 98,377; CST, 1:200). Sections $4 \mu \mathrm{m}$ were placed on glue-coated glass slides (PRO-01, Matsunami, Japan). Human tonsil sections were used as positive controls for CD8, Foxp3 and CD4. A negative control was performed by omitting the primary antibody. All conditions and procedures were defined as in our previous studies [23]. Tumoural parenchyma (tumour bed) was distinguished from the stroma using HE staining and the levels of CD8, Foxp3 and CD4 expression were counted manually under 10 randomly selected highpower fields (400X) for each slide. Areas of the tumour with haemorrhage or necrosis were avoided. Median values were used for cut-offs and the patient cohort was separated into high and low groups, as described in our previous study [23].
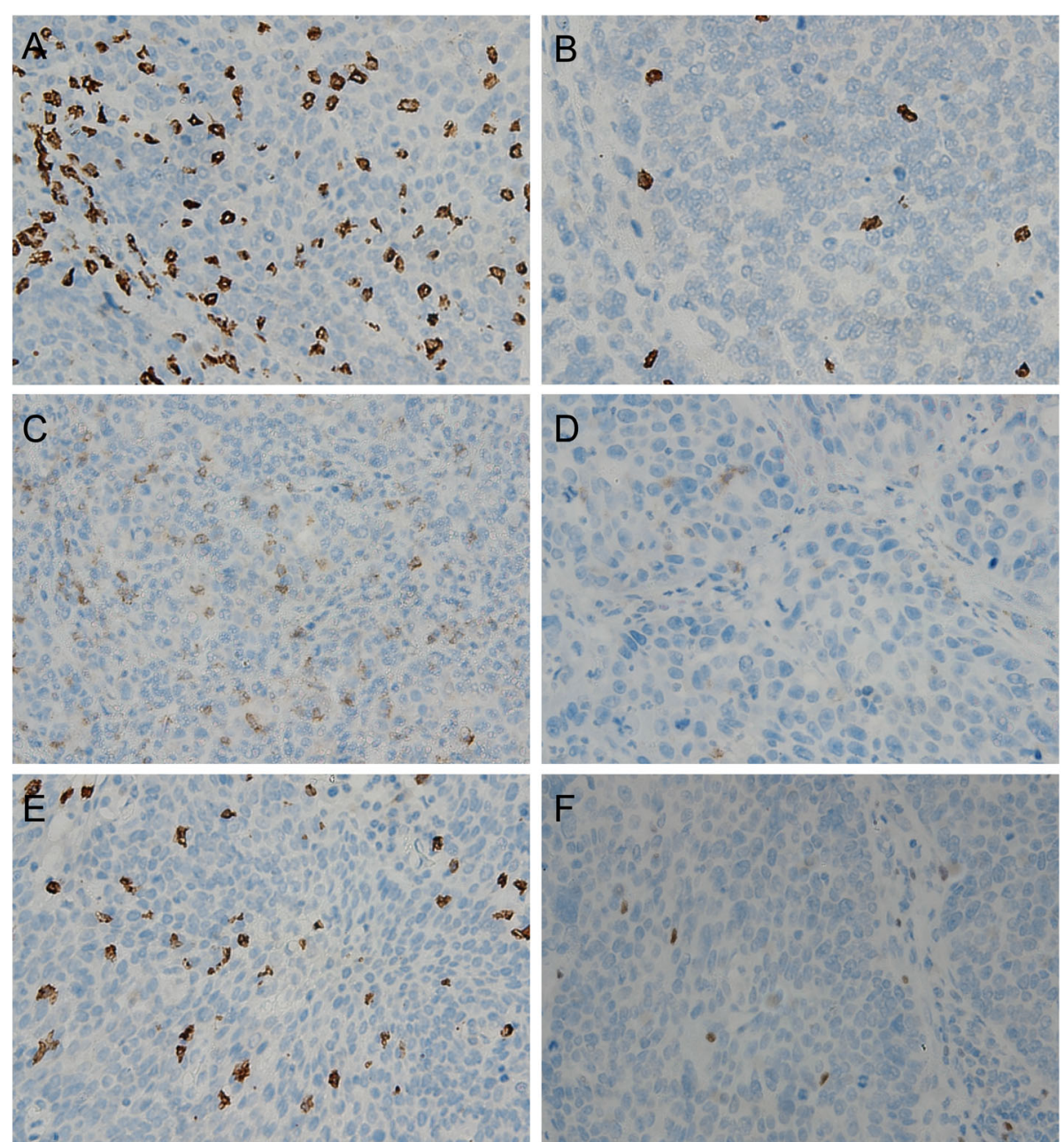

Fig. 1 Immunohistochemical staining of CD8, CD4, and Foxp3 in the HPSCC cohort. a CD8 $8^{\text {high }}$ and $\mathbf{b}$ CD8 $8^{\text {low }}$ infiltration (200x); c CD4 ${ }^{\text {high }}$ infiltration and $\mathbf{d}$ CD4 $4^{\text {low }}$ infiltration (200x); e Foxp3 $3^{\text {high }}$ infiltration and $\mathbf{f}$ Foxp3 $3^{\text {low }}$ infiltration (200x). Abbreviations: HPSCC, hypopharyngeal squamous cell carcinoma 
Representative images of the immunohistochemical detection of tumour-infiltrating $\mathrm{T}$ lymphocytes are shown in Fig. 1a-f. Two independent pathologists who were blinded to the patient data reviewed the slides. The medians were 80 for CD8 (range 1 to 900), 30 for Foxp3 (range 2 to 300) and 30 for CD4 (range 1to 400), respectively. We also investigated the ratios of CD8/Foxp3 and $\mathrm{CD} 8 / \mathrm{CD} 4$, calculating them for each individual tumour. Similarly, the optimal cut-off points were calculated, along with their medians: the values were 2.50 (range 0.1 to 33.33) for CD8/Foxp3 and 3 (range 0.17 to 150) for CD8/CD4.

\section{Statistical analysis}

Statistical analyses were performed by using SPSS (22.0, IBM, Armonk, NY, USA). Fisher's exact test and the chisquared test were used to evaluate the associations among the variables. The relationships between the different lymphocyte infiltrates were calculated using Pearson's correlation coefficient. The Kaplan-Meier method and log-rank test were conducted to determine the prognosis at different survival end points. We used four clinical end points in this study: 1) overall survival (OS) was defined as the time from surgery until the date of death from any cause; 2) disease-free survival (DFS) was defined as the time from surgery until the date of the first recurrence/metastasis or death from any cause; 3) distant metastasis-free survival (DMFS) was defined as the time from surgery until the date of distant metastasis of the tumour or occurrence of death from any cause; and 4) local relapse-free survival (LRFS) was defined as the time from surgery until the date of local recurrence or death from any cause. Univariate and multivariate analyses (UVA and MVA) of prognostic factors were performed using the Cox proportional hazards model. The multivariate variables were adopted from their prognostic significance in UVA $(P<0.05) . P<0.05$ was considered statistically significant.

\section{Results}

\section{Patient characteristics}

The study cohort included 132 patients in this who were diagnosed with HPSCC, and the clinical characteristics of these patients are summarized in Table 1. The samples included 131 males and 1 female with a median age of 60 years (range: $40-76$ years). Twenty-nine (22\%) patients had higher pathological grading (grade III), and 103 (78\%) patients had lower pathological grading (grades I and II). As described above, the HPSCC patients were divided into 2 groups based on their overall staging group according to the AJCC 7th (American Joint Committee on Cancer) edition cancer staging system: namely overall staging group III (35, patients, $26.5 \%$ ) and IVA or IVB (97 patients, $73.5 \%$ ). Patients
Table 1 Clinicopathological characteristics of 132 patients

\begin{tabular}{|c|c|}
\hline Characteristic & N (\%) \\
\hline \multicolumn{2}{|l|}{ Age at diagnosis } \\
\hline$<60 y$ & $71(53.8)$ \\
\hline$\geq 60 y$ & $61(46.2)$ \\
\hline \multicolumn{2}{|l|}{ Sex } \\
\hline Male & $131(99.2)$ \\
\hline Female & $1(0.8)$ \\
\hline \multicolumn{2}{|l|}{ Smoke history } \\
\hline No & $17(12.9)$ \\
\hline Yes & $115(87.1)$ \\
\hline \multicolumn{2}{|l|}{ Drink history } \\
\hline No & $28(21.2)$ \\
\hline Yes & $104(78.8)$ \\
\hline \multicolumn{2}{|l|}{ Site } \\
\hline Pyriform sinus & $116(87.9)$ \\
\hline Not pyriform sinus & $16(12.1)$ \\
\hline \multicolumn{2}{|l|}{ Grade } \\
\hline $\mathrm{G} 1+\mathrm{G} 2$ & $103(78.0)$ \\
\hline G3 & $29(22.0)$ \\
\hline \multicolumn{2}{|l|}{ Stage } \\
\hline III & $35(26.5)$ \\
\hline IVA/IVB & $97(73.5)$ \\
\hline \multicolumn{2}{|l|}{ T category } \\
\hline $\mathrm{T} 1-3$ & $55(41.7)$ \\
\hline T4a & $77(58.3)$ \\
\hline \multicolumn{2}{|l|}{ N category } \\
\hline No-1 & $55(41.7)$ \\
\hline N2-3 & $77(58.3)$ \\
\hline \multicolumn{2}{|l|}{ Laryngectomy } \\
\hline Total & 77 (58.3) \\
\hline Partial & $55(41.7)$ \\
\hline
\end{tabular}

smoked at least 20 packs of cigarettes per year as many as $115(87.1 \%)$ and smoking less than 20 packs group was 17 (12.9\%). Regarding alcohol consumption, 28 (21.2\%) patients consumed less than $10-40 \mathrm{~g} /$ day, and $104(78.8 \%)$ patients consumed at least $40 \mathrm{~g} /$ day. Most tumours were located in the pyriform sinus (PS).

\section{Follow up}

With a median follow-up of 28.4 months (interquartile range 20.9-39.1 months), the 3-year OS, DFS, DMFS and LRFS for the entire cohort were $68.2 \%$ (95\% confidence interval [CI], 57.8 to $78.6 \%$ ), $62.1 \%$ (95\% CI, 52.1 to $72.1 \%$ ), $72.6 \%$ (95\% CI, 62.2 to $83.0 \%$ ) and $79.7 \%$ (95\% CI, 72.4 to $87.0 \%)$, respectively. During the follow-up period, $42(31.8 \%)$ patients experienced treatment failure. A total of $16(12.1 \%)$ and $17(12.8 \%)$ patients had 
only locoregional recurrence or distant metastasis, respectively, and $9(6.8 \%)$ patients had both.

\section{Association among different variables}

Regarding the correlations of the immune markers with clinicopathological characteristics, high levels of TILs (CD8, Foxp3 and CD4) showed evident correlations with lower histopathological grade. The CD8/Foxp3 ratio was associated with the expression of CD8 and Foxp3, and the $\mathrm{CD} 8 / \mathrm{CD} 4$ ratio correlated with each subtype of $\mathrm{CD} 8$ and CD4 infiltrates $(P<0.05)$. Similarly, Foxp3+ TILs exhibited an association with both overall staging group and $\mathrm{T}$ category $(P=0.048$ and $P=0.046$, respectively). We also found marked correlations among CD8, CD4 and Foxp3 using Pearson's correlation coefficient $(P<$ 0.001 , Fig. 2a-c). Other relationships between immune marker expression and clinicopathological parameters are summarized in Table 2.

\section{Correlation with prognosis}

The Kaplan-Meier curves of 3-year OS, DFS, DMFS, LRFS for patients with TILs and the ratios are shown in Figs. 3-4. The 3-year OS, DFS, DMFS and LRFS rates according to high and low CD8 + TIL density, were $80.9 \%$ vs $56.3,73.2 \%$ vs $51.4,80.4 \%$ vs 64.5 and $77.8 \%$ vs $82.1 \%$, respectively. Significant differences were found between the high and low CD8+ TIL groups in 3-year OS, DFS and DMFS but not in LRFS (Fig. 3a-d). Similarly, a higher Foxp3+ TIL level was also strongly correlated with better OS, DFS and DMFS $(P=0.001, P=0.028$ and $P=0.009$, respectively, Fig. 3e-h). Further analysis revealed that patients with a high CD8/Foxp3 ratio had significantly better DFS and DMFS $(P=0.013$ and $P=$ 0.029, respectively) (Fig. 4b-c), while a higher CD8/CD4 ratio evidently improved 3-year DFS and LRFS compared with a lower $\mathrm{CD} 8 / \mathrm{CD} 4$ ratio $(P=0.021$ and $P=$ 0.033 , respectively) (Fig. 4f, h). In contrast, no associations were observed between the status of the CD8/ Foxp3 ratio or the CD8/CD4 ratio and OS (Fig. 4a, e). Both UVA and MVA were performed to determine the associations between prognosis and clinicopathological variables (Table 3-4). The results revealed that a high ratio of CD8/Foxp3 remained an independent favourable prognostic factor for DFS ( $\mathrm{HR}=2.613$; 95\% CI, $1.203-$ 5.673; $P=0.015)$ and DMFS (HR $=3.606$; $95 \% \mathrm{CI}, 1.334-$ 9.748; $P=0.011)$. Furthermore, the $\mathrm{CD} 8 / \mathrm{CD} 4$ ratio was also an independent prognostic factor for LRFS (HR = 2.418; 95\% CI, 1.043-5.606; $P=0.040$ ) in the MVA. In addition, Foxp3+ TIL, T category and site were found to be independent prognostic factors associated with DMFS, DFS and LRFS, respectively (Table 4).

\section{Discussion}

Our study is the first to evaluate lymphocyte ratios in advanced HPSCC and their correlations with clinicopathological characteristics and prognosis in more than 100 patients who underwent surgery. The results indicated that high ratio of CD8/Foxp3 accurately predicted improved prognosis with better DFS and DMFS, and increased $\mathrm{CD} 8 / \mathrm{CD} 4$ ratio was a markedly indicator of improved LRFS. Although Foxp3+ TILs were an independent prognostic factor for DMFS, we could not demonstrate any significant association between CD8+ TIL expression and clinical outcomes in MVA.

In recent years, it has become clear that assessing immune infiltration is of greater prognostic significance in a variety of tumours [15]. CD8+ CTLs are directly capable of killing tumour cells and positively affect prognosis in a broad range of tumour types, including breast cancer, ovarian cancer, head and neck cancer and lung cancer [24-27]. In accordance with previous results, we demonstrated that higher CD8+ infiltration is associated with longer OS, DFS and DMFS in UVA. However, several other studies indicated that there is no such correlation with prognosis. One study even found a negative effect of CD8+ TILs on survival, but this did not reach statistical significance in multivariate analysis [28-30]. In contrast, as one of the paradoxically functional components of the tumour-related immune system, Foxp3+ TILs are considered to be the most specific Treg marker involved in maintaining immune tolerance to the host. In tumour progression, Tregs produce the inhibitory
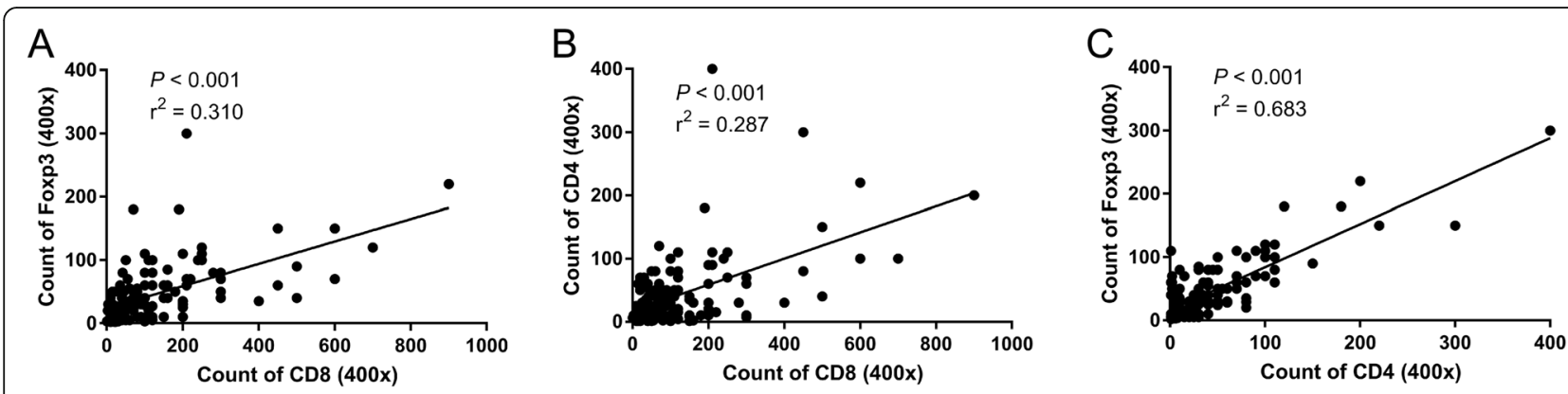

Fig. 2 Correlations of the numbers of $\mathbf{a}$ CD8 and Foxp3, b CD8 and CD4, and $\mathbf{c} C D 8$ and Foxp3 infiltrating lymphocytes $(P<0.001)$ 
Table 2 Associations between the clinicopathological factors of HPSCC with the status of CD8, CD4, and Foxp3 infiltration and the CD8/Foxp3 and CD8/CD4 ratios $(N=132)$

\begin{tabular}{|c|c|c|c|c|c|c|c|c|c|c|c|c|c|c|c|}
\hline \multirow[t]{2}{*}{ Characteristic } & \multicolumn{2}{|c|}{ CD8 } & \multirow[t]{2}{*}{$P$} & \multicolumn{2}{|l|}{ CD4 } & \multirow[t]{2}{*}{$P$} & \multicolumn{2}{|c|}{ Foxp3 } & \multirow[t]{2}{*}{$P$} & \multicolumn{2}{|c|}{ CD8/Foxp3 } & \multirow[t]{2}{*}{$P$} & \multicolumn{2}{|c|}{ CD8/CD4 } & \multirow[t]{2}{*}{$P$} \\
\hline & low & high & & low & high & & low & high & & low & high & & low & high & \\
\hline Age at diagnosis & & & $0.033^{*}$ & & & 0.295 & & & 0.727 & & & 0.166 & & & 0.861 \\
\hline$<60 y$ & 31 & 40 & & 31 & 40 & & 37 & 34 & & 33 & 38 & & 34 & 37 & \\
\hline$\geq 60 y$ & 38 & 23 & & 33 & 28 & & 29 & 32 & & 36 & 25 & & 31 & 30 & \\
\hline Sex & & & 1.000 & & & 1.000 & & & 1.000 & & & 1.000 & & & 0.492 \\
\hline Male & 1 & 0 & & 0 & 1 & & 0 & 1 & & 1 & 0 & & 1 & 0 & \\
\hline Female & 68 & 63 & & 64 & 67 & & 66 & 65 & & 68 & 63 & & 64 & 67 & \\
\hline Smoke history & & & 0.124 & & & 0.120 & & & 0.604 & & & 0.124 & & & 0.072 \\
\hline No & 12 & 5 & & 5 & 12 & & 7 & 10 & & 12 & 5 & & 12 & 5 & \\
\hline Yes & 57 & 58 & & 59 & 56 & & 59 & 56 & & 57 & 58 & & 53 & 62 & \\
\hline Drink history & & & 0.671 & & & 0.834 & & & 0.832 & & & 1.000 & & & 0.832 \\
\hline No & 16 & 12 & & 13 & 15 & & 13 & 15 & & 15 & 13 & & 13 & 15 & \\
\hline Yes & 53 & 51 & & 51 & 53 & & 53 & 51 & & 54 & 50 & & 52 & 52 & \\
\hline Site & & & 0.064 & & & 0.290 & & & 0.059 & & & 0.433 & & & 0.948 \\
\hline Pyriform sinus & 57 & 59 & & 54 & 62 & & 54 & 62 & & 59 & 57 & & 57 & 59 & \\
\hline Not pyriform sinus & 12 & 4 & & 10 & 6 & & 12 & 4 & & 10 & 6 & & 8 & 8 & \\
\hline Grade & & & $0.003^{*}$ & & & $0.037^{*}$ & & & $0.003^{*}$ & & & 0.834 & & & 0.835 \\
\hline $\mathrm{G} 1+\mathrm{G} 2$ & 61 & 42 & & 55 & 48 & & 59 & 44 & & 53 & 50 & & 50 & 53 & \\
\hline G3 & 8 & 21 & & 9 & 20 & & 7 & 22 & & 16 & 13 & & 15 & 14 & \\
\hline Stage & & & 0.238 & & & 0.554 & & & $0.048^{*}$ & & & 0.609 & & & 1.000 \\
\hline III & 15 & 20 & & 15 & 20 & & 12 & 23 & & 17 & 18 & & 17 & 18 & \\
\hline IVA/IVB & 54 & 43 & & 49 & 48 & & 54 & 43 & & 52 & 45 & & 48 & 49 & \\
\hline T category & & & 0.205 & & & 0.589 & & & $0.046^{*}$ & & & 0.449 & & & 0.718 \\
\hline $\mathrm{T} 1-3$ & 40 & 44 & & 39 & 45 & & 36 & 48 & & 46 & 38 & & 40 & 44 & \\
\hline T4a & 29 & 19 & & 25 & 23 & & 30 & 18 & & 23 & 25 & & 25 & 23 & \\
\hline N category & & & 1.000 & & & 0.599 & & & 0.289 & & & 0.536 & & & 0.860 \\
\hline No-1 & 29 & 26 & & 25 & 30 & & 24 & 31 & & 27 & 28 & & 28 & 27 & \\
\hline N2-3 & 40 & 37 & & 39 & 38 & & 42 & 35 & & 42 & 35 & & 37 & 40 & \\
\hline Laryngectomy & & & 0.379 & & & 0.599 & & & 0.480 & & & 0.725 & & & 0.295 \\
\hline Total & 43 & 34 & & 39 & 38 & & 41 & 36 & & 39 & 38 & & 41 & 36 & \\
\hline Partial & 26 & 29 & & 25 & 30 & & 25 & 30 & & 30 & 25 & & 24 & 31 & \\
\hline CD8 (cut off: 80) & & & & & & $0.001^{*}$ & & & $<0.001^{*}$ & & & $0.001^{*}$ & & & $0.039^{*}$ \\
\hline Low & & & & 43 & 26 & & 50 & 19 & & 46 & 23 & & 40 & 29 & \\
\hline High & & & & 21 & 42 & & 16 & 47 & & 23 & 40 & & 25 & 38 & \\
\hline CD4 (cut off: 30) & & & $0.001^{*}$ & & & & & & $<0.001^{*}$ & & & 0.163 & & & $<0.001^{*}$ \\
\hline Low & 43 & 21 & & & & & 49 & 15 & & 29 & 35 & & 15 & 49 & \\
\hline High & 26 & 42 & & & & & 17 & 51 & & 40 & 28 & & 50 & 18 & \\
\hline Foxp3 (cut off: 30) & & & $<0.001^{*}$ & & & $<0.001^{*}$ & & & & & & $0.014^{*}$ & & & \\
\hline Low & 50 & 16 & & 49 & 17 & & & & & 27 & 39 & & 29 & 37 & 0.296 \\
\hline High & 19 & 47 & & 15 & 51 & & & & & 42 & 24 & & 36 & 30 & \\
\hline
\end{tabular}

Abbreviations: HPSCC hypopharyngeal squamous cell carcinoma, G1 Well differentiated, G2 Moderately differentiated, G3 Poorly differentiated *The $P$ value is significant 
A

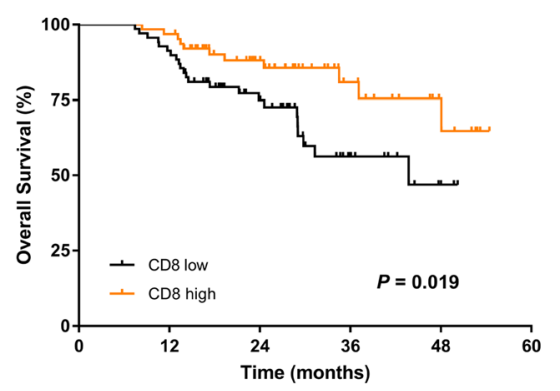

B

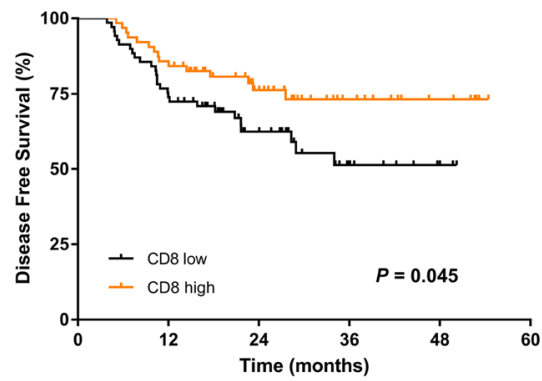

C

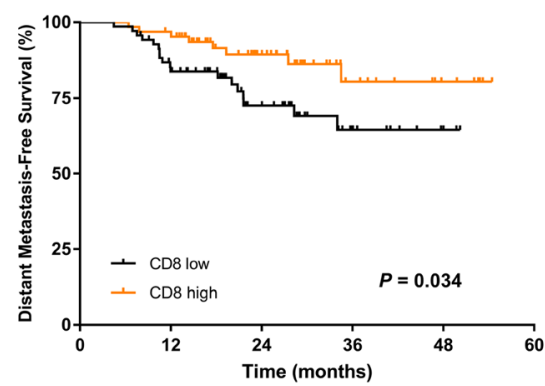

D

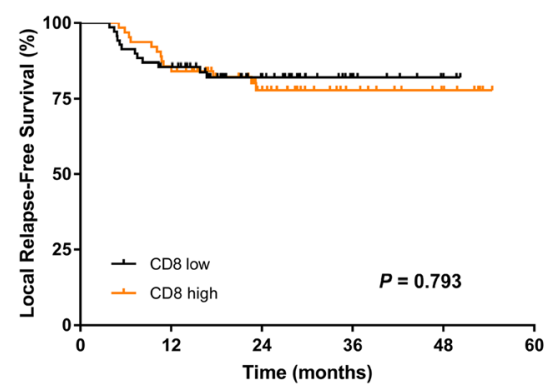

E

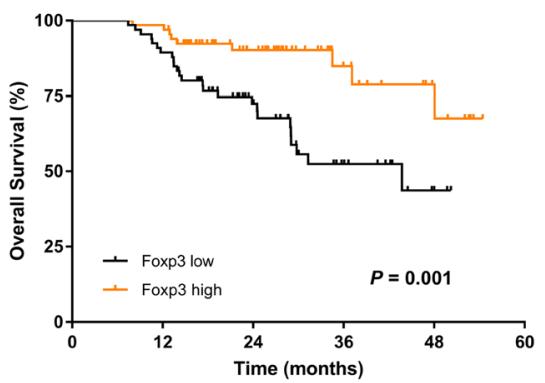

F

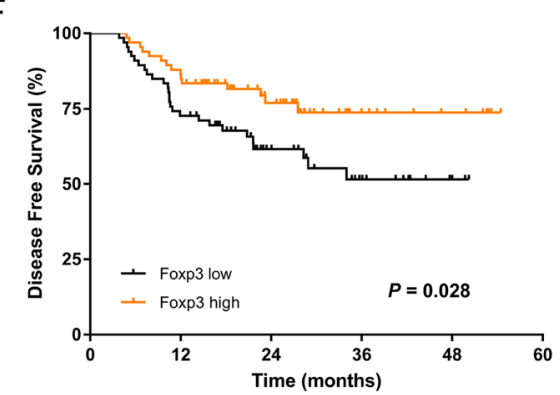

G

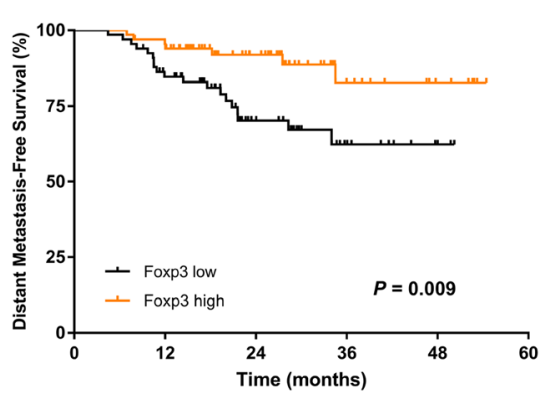

$\mathrm{H}$

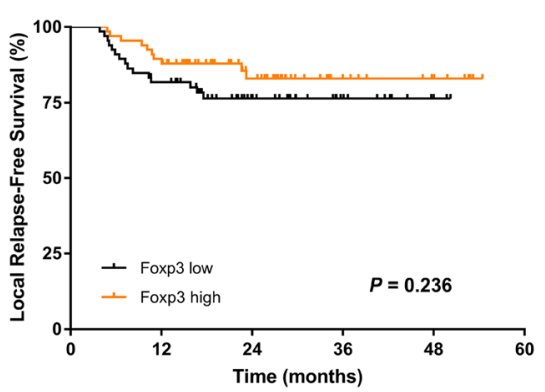

Fig. 3 Kaplan-Meier curves of (a) overall survival, b disease-free survival, c distant metastasis-free survival, and d local relapse-free survival for patients stratified by high CD8 and low CD8 immune cell infiltration; e overall survival, $\mathbf{f}$ disease-free survival, $\mathbf{g}$ distant metastasis-free survival, and $\mathbf{h}$ local relapse-free survival for patients stratified by high and low Foxp3 immune cell infiltration. $P$ values were calculated by the log-rank test

cytokines interleukin 10, transforming growth factor $\beta$ and haemoglobin oxygenase 1 to achieve immune escape [31]. Therefore, many studies have suggested that higher Foxp3 Treg infiltration is associated with poor prognosis in various malignancies including breast, lung, cervical, oral cavity and ovarian cancers [32, 33]. On the other hand, accumulating evidence has emerged that in other cancers, including HPSCC, their presence was associated with better prognosis [23, 34-36]. To date, the role of Foxp3 regulator $\mathrm{T}$ cells in cancer is still conflicting. Assessing cytotoxic CD8+ T cells and regulatory Foxp3 $\mathrm{T}$ cells together, as the two major components of the 
A

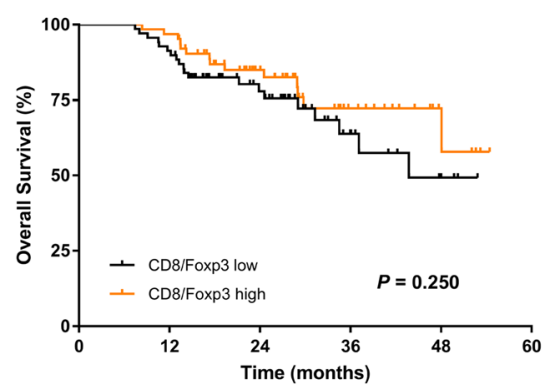

B

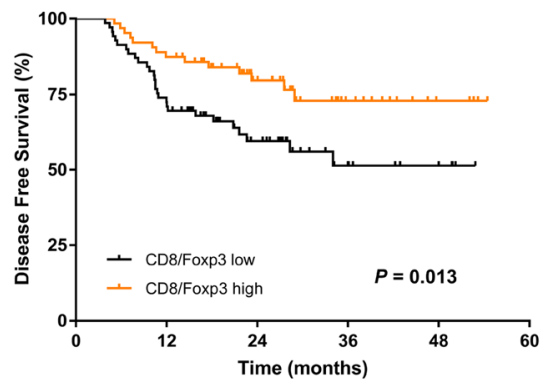

C

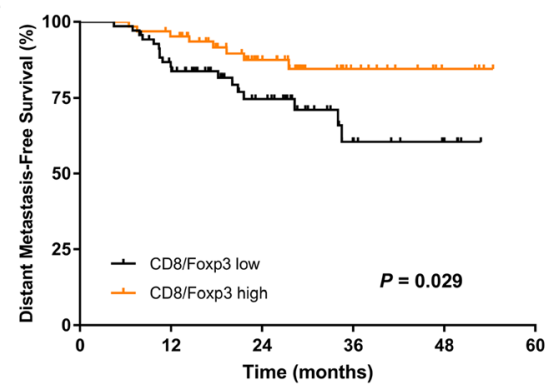

D

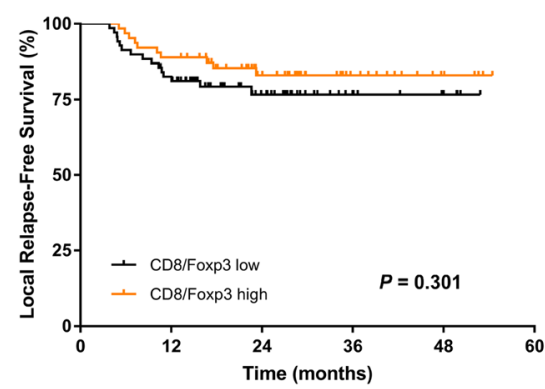

E

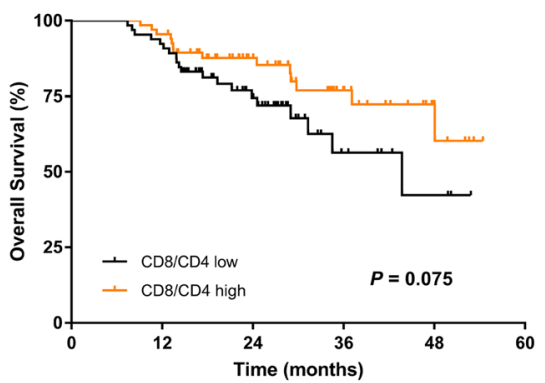

F

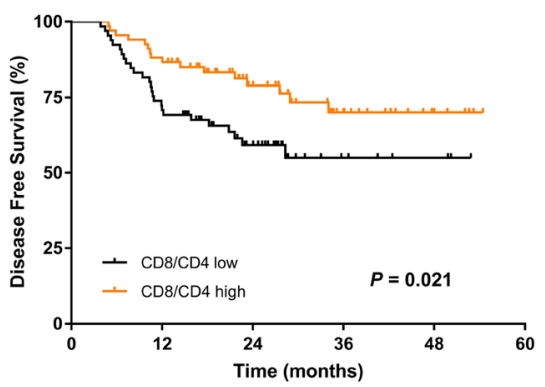

G

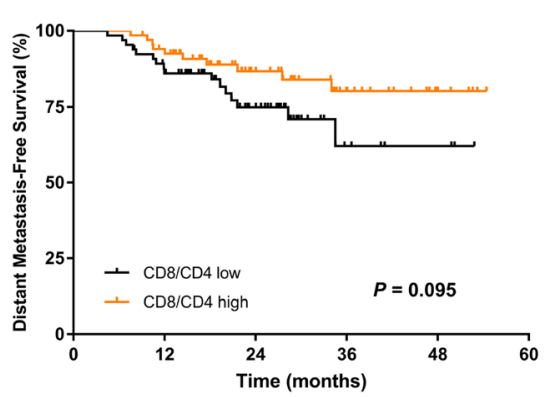

$\mathrm{H}$

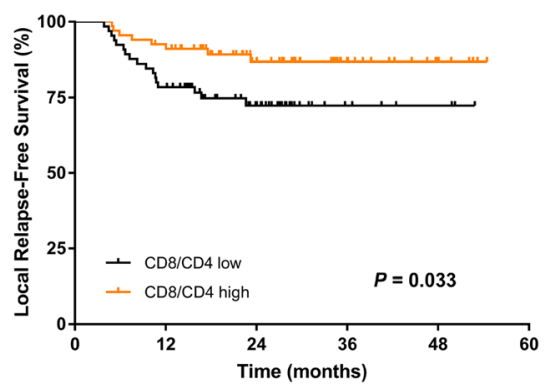

Fig. 4 Kaplan-Meier curves of (a) overall survival, b disease-free survival, c distant metastasis-free survival, and d local relapse-free survival for patients stratified by high and low CD8/Foxp3 ratios; e overall survival, $\mathbf{f}$ disease-free survival, $\mathbf{g}$ distant metastasis-free survival, and $\mathbf{h}$ local relapse-free survival for patients stratified by high and low CD8/CD4 ratios. $P$ values were calculated by the log-rank test

tumour-related immune system, could provide more precise estimates of their effects on HPSCC patient survival. The present study also demonstrated that higher Foxp3 TIL density in UVA led to significantly better OS, DFS and DMFS outcomes, but only DMFS had independent prognostic significance in MVA, which is slightly different from the findings of our previous study
[23]. Furthermore, the current data showed that CD4 TIL density had no impact on survival but showed strong correlations with CD8 and Foxp3. We assumed that the presence of $\mathrm{CD} 4 \mathrm{~T}$ cells alone is not associated with prognosis and that these cells may interact with other subsets, exerting many more effects in the tumour microenvironment. 
Table 3 Univariate analyses of OS, DFS, DMFS and LRFS in the entire population $(N=132)$

\begin{tabular}{|c|c|c|c|c|c|c|c|c|c|c|c|c|}
\hline \multirow[t]{2}{*}{ Variable } & \multicolumn{3}{|l|}{ OS } & \multicolumn{3}{|l|}{ DFS } & \multicolumn{3}{|l|}{ DMFS } & \multicolumn{3}{|l|}{ LRFS } \\
\hline & $\mathrm{HR}$ & $95 \% \mathrm{Cl}$ & $P$ & $\mathrm{HR}$ & $95 \% \mathrm{Cl}$ & $P$ & $\mathrm{HR}$ & $95 \% \mathrm{Cl}$ & $P$ & $\mathrm{HR}$ & $95 \% \mathrm{Cl}$ & $P$ \\
\hline Age, years ( $\geq 60 y$ vs $<60 y$ ) & 0.521 & $0.254-1.073$ & 0.077 & 0.637 & $0.341-1.188$ & 0.156 & 0.787 & $0.361-1.715$ & 0.547 & 0.594 & $0.263-1.346$ & 0.212 \\
\hline Smoke (Yes vs No) & 0.596 & $0.259-1.372$ & 0.224 & 0.738 & $0.328-1.662$ & 0.463 & 0.611 & $0.230-1.621$ & 0.322 & 1.753 & $0.413-7.438$ & 0.446 \\
\hline Drink history (Yes vs No) & 0.748 & $0.348-1.607$ & 0.457 & 0.945 & $0.452-1.976$ & 0.881 & 0.822 & $0.330-2.050$ & 0.675 & 1.991 & $0.596-6.653$ & 0.263 \\
\hline Site (Nat $P S$ us $P S$ ) & 2.534 & $1.144-5.610$ & $0.022^{*}$ & 2.524 & $1.206-5.284$ & $0.014^{*}$ & 2.629 & $1.054-6.556$ & $0.038^{*}$ & 2.600 & $1.038-6.513$ & $0.041^{*}$ \\
\hline Grade (G3 vs G2 + G1) & 0.689 & $0.285-1.665$ & 0.408 & 1.033 & $0.508-2.102$ & 0.929 & 1.283 & $0.539-3.053$ & 0.573 & 1.586 & $0.684-3.675$ & 0.282 \\
\hline Stage (IVA/IVB vs III) & 1.785 & $0.739-4.313$ & 0.198 & 2.457 & $1.035-5.834$ & $0.042^{*}$ & 0.208 & $0.049-0.880$ & $0.033^{*}$ & 2.848 & $0.852-9.518$ & 0.089 \\
\hline T category (T4a vs T1-3) & 2.259 & $1.151-4.436$ & $0.018^{*}$ & 2.508 & $1.365-4.610$ & $0.003^{*}$ & 2.681 & $1.231-5.842$ & $0.013^{*}$ & 2.069 & $0.944-4.538$ & 0.070 \\
\hline N category (N2-3 vs N0-1) & 1.319 & $0.652-2.666$ & 0.441 & 1.682 & $0.874-3.236$ & 0.120 & 1.681 & $0.731-3.868$ & 0.222 & 2.361 & $0.943-5.915$ & 0.067 \\
\hline Laryngectomy (Total vs Partial) & 1.896 & $0.853-4.215$ & 0.117 & 1.860 & $0.951-3.638$ & 0.070 & 2.233 & $0.894-5.578$ & 0.085 & 2.370 & $0.946-5.938$ & 0.066 \\
\hline CD8 (Low vs High) & 2.324 & $1.127-4.795$ & $0.022^{*}$ & 1.892 & $1.005-3.560$ & $0.048^{*}$ & 2.391 & $1.038-5.505$ & $0.040^{*}$ & 0.900 & $0.411-1.974$ & 0.793 \\
\hline CD4 (Low vs High) & 1.174 & $0.593-2.323$ & 0.645 & 1.119 & $0.610-2.052$ & 0.717 & 1.656 & $0.749-3.661$ & 0.212 & 0.968 & $0.442-2.123$ & 0.936 \\
\hline Foxp3 (Low vs High) & 3.253 & $1.511-7.001$ & $0.003^{*}$ & 1.999 & $1.063-3.760$ & $0.032^{*}$ & 3.006 & $1.263-7.153$ & $0.013^{*}$ & 1.615 & $0.726-3.596$ & 0.240 \\
\hline CD8/Foxp3 (Low vs High) & 1.490 & $0.752-2.953$ & 0.253 & 2.205 & $1.159-4.195$ & $0.016^{*}$ & 2.463 & $1.069-5.674$ & $0.034^{*}$ & 1.522 & $0.683-3.391$ & 0.305 \\
\hline CD8/CD4 (Low vs High) & 1.857 & $0.930-3.705$ & 0.079 & 2.058 & $1.099-3.851$ & $0.024^{*}$ & 1.947 & $0.878-4.317$ & 0.101 & 2.424 & $1.046-5.621$ & 0030 \\
\hline
\end{tabular}

Abbreviations: PS Pyriform sinus, OS Overall survival, DFS Disease-free survival, DMFS Distant metastasis-free survival, LRFS Local relapse-free survival, G1 Well differentiated, G2 Moderately differentiated, G3 Poorly differentiated

*The $P$ value is significant

We measured the relative number of TILs and explored the association between different subsets, and the data indicated positive correlations among CD8, Foxp3 and CD4 T cells. As an indicator of the balance between CD8+ TILs and Foxp3 Tregs in the tumour microenvironment, the CD8/Foxp3 ratio appeared to be useful for predicting clinical outcomes. In reviewing the literature, we found that the CD8/Foxp3 ratio had a positive effect on prognosis in a number of tumours, including osteosarcoma, colorectal cancer and breast cancer [21, 33, 37-39]. For patients with tonsillar cancer, a high CD8/Foxp3+ ratio positively correlated with DFS [40]. Ni et al. reported that increased CD8/Foxp3 ratios were associated with improved OS, DFS and tumour stage in tongue cancer but were not an independent prognostic factor in MVA [28].
Similar to these studies, this cohort demonstrated that a high CD8/Foxp3 ratio correlated with favourable prognosis and CD8 expression, which further confirmed that CD8+ TILs are associated with good prognosis in advanced HPSCC patients. Additionally, when using different survival end points, the CD8/Foxp3 ratio consistently served as an independent prognostic factor for DFS and DMFS in MVA. A large meta-analysis of TIL phenotyping, encompassing 33 studies and nearly 10,000 patients, indicated that lymphocyte ratios, particularly the CD8/Foxp3 ratio, have more prognostic potential than individual lymphocytic subtypes [31]. Although an investigation showed no significant correlation between the CD8/Foxp3 ratio and survival in ovarian cancer [41], the CD8/Foxp3 ratio was found to be a promising prognostic marker in

Table 4 Multivariate analyses of OS, DFS, DMFS and LRFS in the entire population $(N=132)$

\begin{tabular}{|c|c|c|c|c|c|c|c|c|c|c|c|c|}
\hline \multirow[t]{2}{*}{ Variable } & \multicolumn{3}{|l|}{ OS } & \multicolumn{3}{|l|}{ DFS } & \multicolumn{3}{|l|}{ DMFS } & \multicolumn{3}{|l|}{ LRFS } \\
\hline & $\mathrm{HR}$ & $95 \% \mathrm{Cl}$ & $P$ & $\mathrm{HR}$ & $95 \% \mathrm{Cl}$ & $P$ & $\mathrm{HR}$ & $95 \% \mathrm{Cl}$ & $P$ & $\mathrm{HR}$ & $95 \% \mathrm{Cl}$ & $P$ \\
\hline Site (Not PS vs PS) & 1.621 & $0.706-3.726$ & 0.255 & 1.756 & $0.810-3.807$ & 0.154 & 1.549 & $0.614-3.909$ & 0.354 & 2.590 & $1.034-6.491$ & $0.042^{*}$ \\
\hline Stage (IVA/IVB vs III) & & & & 1.496 & $0.563-3.979$ & 0.419 & 2.489 & $0.530-11.688$ & 0.248 & & & \\
\hline T category (T4a vs T1-3) & 1.880 & $0.947-3.735$ & 0.071 & 2.196 & $1.077-4.476$ & $0.030^{*}$ & 2.115 & $0.911-4.911$ & 0.081 & & & \\
\hline CD8 (Low vs High) & 1.231 & $0.509-2.977$ & 0.644 & 0.716 & $0.300-1.709$ & 0.452 & 0.698 & $0.217-2.242$ & 0.546 & & & \\
\hline Foxp3 (Low vs High) & 2.387 & $0.932-6.111$ & 0.070 & 2.066 & $0.885-4.826$ & 0.094 & 3.253 & $1.038-10.196$ & $0.043^{*}$ & & & \\
\hline CD8/Foxp3 (Low vs High) & & & & 2.613 & $1.203-5.673$ & $0.015^{*}$ & 3.606 & $1.334-9.748$ & $0.011^{*}$ & & & \\
\hline CD8/CD4 (Low vs High) & & & & 1.708 & $0.871-3.349$ & 0.119 & & & & 2.418 & $1.043-5.606$ & $0.040^{*}$ \\
\hline
\end{tabular}

Multivariate cox regression analyses were performed for all variables that were significantly associated with survival in univariate analysis

Abbreviations: PS Pyriform sinus, OS Overall survival, DFS Disease-free survival, DMFS distant metastasis-free survival, LRFS Local relapse-free survival, G1 Well differentiated, G2 Moderately differentiated, G3 poorly differentiated

*The $P$ value is significant 
advanced HPSCC. Additionally, the current study also identified that a high CD8/CD4 ratio was associated with better DMFS and LRFS in UVA and was an independent prognostic factor for LRFS in MVA, although CD4 infiltrating $\mathrm{T}$ cells alone were not significantly correlated with survival implications. Consistent with our results, previous studies have reported that a high stromal CD8/CD4 ratio was found to be an independent favourable prognostic factor in oral squamous cell carcinoma, and one study revealed that the $\mathrm{CD} 8 / \mathrm{CD} 4$ ratio was higher in cases without metastasis and in low-grade lesions [42, 43]. Moreover, studies in lung cancer suggested that the CD8/ $\mathrm{CD} 4$ ratio in patients in the non-metastasis group was remarkably higher, and these patients had a significantly better overall survival rate than patients with a low CD8/ CD4 ratio [44, 45]. Other studies of different lesions also observed that higher $\mathrm{CD} 8 / \mathrm{CD} 4$ ratios were associated with improved outcome $[46,47]$. In addition, high CD8/CD4 was associated with improved short-term survival in head and neck squamous cell carcinoma and was significantly correlated with the absence of lymph node metastases in cervical carcinomas, thus indicating a favourable prognosis $[48,49]$. However, there were also instances in which CD8/CD4 ratio was not linked to clinical outcomes, and some researchers even reported that a high $\mathrm{CD} 8 / \mathrm{CD} 4$ ratio was associated with alcohol use and poor tumour differentiation [50]. In general, the tendency for better clinical outcomes of patients with a high $\mathrm{CD} 8 / \mathrm{CD} 4$ ratio is notable in HPSCC, despite the prognostic significance being very different from that in other tumours. It is also noteworthy that the current study found Foxp3 to be an independent prognostic factor for DMFS, whereas CD8 did not show any significance in MVA. These results were different from those of previous study because lymphocyte ratios were included in the MVA of this cohort, which again supported the idea that the CD8/Foxp3 and CD8/CD4 ratios were more indicative of prognosis than each subtype alone. Altogether, these findings confirm that not only the infiltration density of TIL subsets but also the ratios of TILs, particularly the CD8/Foxp3 and CD8/CD4 ratios, have important impacts on patient outcomes and could potentially be taken into account when considering patient prognostication and treatment stratification. In the era of immunotherapy, these immune biomarkers may provide new clues to therapeutic strategies and are speculated to be possible predictive markers of treatment efficacy. Further studies are needed to validate the results of the present study in a large cohort with neoadjuvant settings.

Although the present results are very promising, there are some limitations. First, all the markers in this study are for the advanced clinical stage of HPSCC (III and IVA), and early clinical stage (I-II) cases are also needed for further testing. Second, a short follow-up resulted in a limited number of patients with locoregional recurrence and distant metastasis. Third, this study cohort consisted of 131 males and 1 female who underwent surgical treatment because most female patients chose laryngeal preservation treatment. Further investigations are warranted to overcome these limitations as much as possible.

\section{Conclusion}

This study demonstrated that high TIL levels are of prognostic significance in HPSCC, while the ratios between these subsets may be more informative. We stressed that a high ratio of CD8/Foxp3 accurately predicted prognosis for improved DFS and DMFS, and an increased CD4/CD8 ratio was an independent prognostic factor for better LRFS. These findings will improve our understanding of the clinical significance of immune cells in HPSCC.

\begin{abstract}
Abbreviations
HPSCC: Hypopharyngeal squamous cell carcinoma; CCRT: Concurrent chemoradiation therapy; TILs: Tumour-infiltrating lymphocytes; CTLs: Cytotoxic T lymphocytes; NSCLC: Non-small cell lung cancer; Tregs: Regulatory T cells; HE: Haematoxylin-eosin; IHC: Immunohistochemical; OS: Overall survival; DFS: Disease-free survival; DMFS: Distant metastasis-free survival; LRFS: Local relapse-free survival; MVA: Multivariate analysis; UVA: Univariate analysis; AJCC: American Joint Committee on Cancer; PS: Pyriform sinus
\end{abstract}

\section{Acknowledgements}

We would like to thank American Journal Experts (AJE) for editing the language.

\section{Authors' contributions}

WJ wrote the manuscript; HCY designed the study; TS and WJ performed the data analysis; TS and HCY gathered the clinical information and tissue samples; TS followed up the patients; ZJH and SJ performed

immunohistochemistry; HCY and LL performed evaluations and revised the data; HCY and WJ revised the manuscript and gave final approval to the manuscript. All authors have read and approved the manuscript.

\section{Funding}

Not applicable.

\section{Availability of data and materials}

The datasets used and analysed during the current study are available from the corresponding author on reasonable request.

\section{Ethics approval and consent to participate}

This study was approved by the Institutional Ethics Committee of The Science and Technology Commission of Shanghai Municipality, and was carried out in accordance with the Declaration of Helsinki. Written informed consent was obtained from all participants.

Consent for publication

Not applicable.

\section{Competing interests}

No author has financial or other contractual agreements that might cause conflicts of interest.

\section{Author details}

'Department of Radiotherapy, Eye \& ENT Hospital, Fudan University, Shanghai, China. ${ }^{2}$ Department of Radiotherapy, Eye \& ENT Hospital, Fudan University, Shanghai, China. ${ }^{3}$ Department of Pathology, Eye \& ENT Hospital, Fudan University, 2600 jiangyue Road, Shanghai 201112, China. 
Received: 5 April 2020 Accepted: 29 July 2020

Published online: 05 August 2020

\section{References}

1. Weller P, Bankfalvi A, Gu X, Dominas N, Lehnerdt GF, Zeidler R, Lang S, Brandau S, Dumitru CA. The role of tumour FoxP3 as prognostic marker in different subtypes of head and neck cancer. Eur J Cancer. 2014;50(7):1291-300.

2. Ono T, Azuma K, Kawahara A, Akiba J, Kakuma T, Chitose S, Umeno H. Pretreatment CD8(+) tumour-infiltrating lymphocyte density predicts distant metastasis after definitive treatment in patients with stage III/IV hypopharyngeal squamous cell carcinoma. Clinical Otolaryngol. 2018;43(5): 1312-20.

3. Petersen JF, Timmermans AJ, van Dijk BAC, Overbeek LIH, Smit LA, Hilgers FJM, Stuiver MM, van den Brekel MWM. Trends in treatment, incidence and survival of hypopharynx cancer: a 20-year population-based study in the Netherlands. Eur Arch Otorhinolaryngol. 2018;275(1):181-9.

4. Newman JR, Connolly TM, Illing EA, Kilgore ML, Locher JL, Carroll WR. Survival trends in hypopharyngeal cancer: a population-based review. Laryngoscope. 2015;125(3):624-9.

5. Saifi M, Maran A, Raynaud P, Picot MC, Quittet P, Cartron G, Rossi JF, Costes $\checkmark$. High ratio of interfollicular CD8/FOXP3-positive regulatory $T$ cells is associated with a high FLIPI index and poor overall survival in follicular lymphoma. Exp Ther Med. 2010;1(6):933-8.

6. Rosenberg SA, Spiess P, Lafreniere R. A new approach to the adoptive immunotherapy of cancer with tumor-infiltrating lymphocytes. Science. 1986;233(4770):1318-21.

7. Giatromanolaki A, Banham AH, Harris AL, Koukourakis MI. FOXP3 infiltrating lymphocyte density and PD-L1 expression in operable non-small cell lung carcinoma. Exp Lung Res. 2019;45(3-4):76-83.

8. Ou D, Adam J, Garberis I, Blanchard P, Nguyen F, Levy A, Casiraghi O, Gorphe P, Breuskin I, Janot F, et al. Clinical relevance of tumor infiltrating lymphocytes, PD-L1 expression and correlation with HPV/p16 in head and neck cancer treated with bio- or chemo-radiotherapy. Oncoimmunology. 2017;6(9):e1341030.

9. Luen SJ, Savas P, Fox SB, Salgado R, Loi S. Tumour-infiltrating lymphocytes and the emerging role of immunotherapy in breast cancer. Pathology. 2017; 49(2):141-55.

10. Rojas IG, Spencer ML, Zapata PA, Martinez A, Alarcon R, Marchesani FJ, Tezal M. CD8+ and FoxP3+ T-cell infiltration in actinic cheilitis. Int J Dermatol. 2017;56(1):54-62.

11. Harimoto $H$, Shimizu M, Nakagawa Y, Nakatsuka K, Wakabayashi A Sakamoto C, Takahashi H. Inactivation of tumor-specific CD8(+) CTLs by tumor-infiltrating tolerogenic dendritic cells. Immunol Cell Biol. 2013;91(9): 545-55

12. Viguier M, Lemaitre F, Verola O, Cho MS, Gorochov G, Dubertret L, Bachelez $H$, Kourilsky P, Ferradini L. Foxp3 expressing CD4+CD25(high) regulatory T cells are overrepresented in human metastatic melanoma lymph nodes and inhibit the function of infiltrating T cells. J Immunol. 2004;173(2):1444-53.

13. Jackute J, Zemaitis M, Pranys D, Sitkauskiene B, Miliauskas S, Bajoriunas V, Lavinskiene S, Sakalauskas R. The prognostic influence of tumor infiltrating Foxp3(+)CD4(+), CD4(+) and CD8(+) T cells in resected non-small cell lung cancer. J Inflamm. 2015;12:63.

14. Quan H, Yan L, Wang S, Wang S. Clinical relevance and significance of programmed death-ligand 1 expression, tumor-infiltrating lymphocytes, and p16 status in sinonasal squamous cell carcinoma. Cancer Manag Res. 2019; 11:4335-45.

15. De Meulenaere A, Vermassen T, Aspeslagh S, Vandecasteele K, Rottey S, Ferdinande L. TILs in head and neck Cancer: ready for clinical implementation and why (not)? Head Neck Pathol. 2017;11(3):354-63.

16. Mahmoud SM, Paish EC, Powe DG, Macmillan RD, Lee AH, Ellis 10 , Green AR. An evaluation of the clinical significance of FOXP3+ infiltrating cells in human breast cancer. Breast Cancer Res Treat. 2011;127(1):99-108.

17. Curiel TJ, Coukos G, Zou L, Alvarez X, Cheng P, Mottram P, Evdemon-Hogan M, Conejo-Garcia JR, Zhang L, Burow M, et al. Specific recruitment of regulatory $T$ cells in ovarian carcinoma fosters immune privilege and predicts reduced survival. Nat Med. 2004;10(9):942-9.

18. Kim HI, Kim H, Cho HW, Kim SY, Song KJ, Hyung WJ, Park CG, Kim CB. The ratio of intra-tumoral regulatory $T$ cells (Foxp3+)/helper T cells (CD4+) is a prognostic factor and associated with recurrence pattern in gastric cardia cancer. J Surg Oncol. 2011;104(7):728-33.
19. Asano Y, Kashiwagi S, Goto W, Kurata K, Noda S, Takashima T, Onoda N, Tanaka S, Ohsawa M, Hirakawa K. Tumour-infiltrating CD8 to FOXP3 lymphocyte ratio in predicting treatment responses to neoadjuvant chemotherapy of aggressive breast cancer. Br J Surg. 2016;103(7):845-54.

20. Uryvaev A, Passhak M, Hershkovits D, Sabo E, Bar-Sela G. The role of tumorinfiltrating lymphocytes (TILS) as a predictive biomarker of response to antiPD1 therapy in patients with metastatic non-small cell lung cancer or metastatic melanoma. Med Oncol. 2018;35(3):25.

21. Semeraro M, Adam J, Stoll G, Louvet E, Chaba K, Poirier-Colame V, Sauvat A, Senovilla L, Vacchelli E, Bloy N, et al. The ratio of CD8(+)/FOXP3 T lymphocytes infiltrating breast tissues predicts the relapse of ductal carcinoma in situ. Oncoimmunology. 2016;5(10):e1218106.

22. Sideras K, Galjart B, Vasaturo A, Pedroza-Gonzalez A, Biermann K, Mancham S, Nigg AL, Hansen BE, Stoop HA, Zhou G, et al. Prognostic value of intratumoral CD8(+) /FoxP3(+) lymphocyte ratio in patients with resected colorectal cancer liver metastasis. J Surg Oncol. 2018;118(1):68-76.

23. Hu C, Tian S, Lin L, Zhang J, Ding H. Prognostic and clinicopathological significance of PD-L1 and tumor infiltrating lymphocytes in hypopharyngeal squamous cell carcinoma. Oral Oncol. 2020;102:104560.

24. Mao Y, Qu Q, Chen X, Huang O, Wu J, Shen K. The prognostic value of tumor-infiltrating lymphocytes in breast Cancer: a systematic review and meta-analysis. PLoS One. 2016;11(4):e0152500.

25. Hwang WT, Adams SF, Tahirovic E, Hagemann IS, Coukos G. Prognostic significance of tumor-infiltrating $T$ cells in ovarian cancer: a meta-analysis. Gynecol Oncol. 2012;124(2):192-8.

26. Fang J, Li X, Ma D, Liu X, Chen Y, Wang Y, Lui WWY, Xia J, Cheng B, Wang Z. Prognostic significance of tumor infiltrating immune cells in oral squamous cell carcinoma. BMC Cancer. 2017;17(1):375.

27. Geng Y, Shao Y, He W, Hu W, Xu Y, Chen J, Wu C, Jiang J. Prognostic role of tumor-infiltrating lymphocytes in lung Cancer: a meta-analysis. Cellular Physiol Biochem. 2015;37(4):1560-71.

28. Ni YH, Zhang XX, Lu ZY, Huang XF, Wang ZY, Yang $Y$, Dong $Y C$, Jing $Y$, Song $Y$, Hou $Y Y$, et al. Tumor-Infiltrating CD1a(+) DCs and CD8(+)/FoxP3(+) Ratios Served as Predictors for Clinical Outcomes in Tongue Squamous Cell Carcinoma Patients. Pathol Oncol Res. 2020;26(3):1687-95.

29. Machado I, Lopez-Guerrero JA, Scotlandi K, Picci P, Llombart-Bosch A. Immunohistochemical analysis and prognostic significance of PD-L1, PD-1, and CD8+ tumor-infiltrating lymphocytes in Ewing's sarcoma family of tumors (ESFT). Virchows Archiv. 2018;472(5):815-24.

30. Wakabayashi O, Yamazaki K, Oizumi S, Hommura F, Kinoshita I, Ogura S, Dosaka-Akita H, Nishimura M. CD4+ T cells in cancer stroma, not CD8+ T cells in cancer cell nests, are associated with favorable prognosis in human non-small cell lung cancers. Cancer Sci. 2003;94(11):1003-9.

31. Fridman WH, Pages F, Sautes-Fridman C, Galon J. The immune contexture in human tumours: impact on clinical outcome. Nat Rev Cancer. 2012;12(4): 298-306.

32. Watanabe $Y$, Katou F, Ohtani H, Nakayama T, Yoshie O, Hashimoto K. Tumor-infiltrating lymphocytes, particularly the balance between CD8(+) T cells and CCR4(+) regulatory T cells, affect the survival of patients with oral squamous cell carcinoma. Oral Surg Oral Med Oral Pathol Oral Radiol Endod. 2010;109(5):744-52.

33. Peng GL, Li L, Guo YW, Yu P, Yin XJ, Wang S, Liu CP. CD8(+) cytotoxic and FoxP3(+) regulatory $T$ lymphocytes serve as prognostic factors in breast cancer. Am J Transl Res. 2019;11(8):5039-53.

34. Balermpas P, Michel Y, Wagenblast J, Seitz O, Weiss C, Rodel F, Rodel C, Fokas E. Tumour-infiltrating lymphocytes predict response to definitive chemoradiotherapy in head and neck cancer. Br J Cancer. 2014;110(2):501-9.

35. Ohtani H. Focus on TILs: prognostic significance of tumor infiltrating lymphocytes in human colorectal cancer. Cancer Immun. 2007;7:4.

36. Schumacher K, Haensch W, Roefzaad C, Schlag PM. Prognostic significance of activated CD8(+) T cell infiltrations within esophageal carcinomas. Cancer Res. 2001;61(10):3932-6.

37. Fritzsching B, Fellenberg J, Moskovszky L, Sapi Z, Krenacs T, Machado I, Poeschl J, Lehner B, Szendroi M, Bosch AL, et al. CD8(+)/FOXP3(+)-ratio in osteosarcoma microenvironment separates survivors from non-survivors: a multicenter validated retrospective study. Oncoimmunology. 2015;4(3): e990800.

38. Suzuki H, Chikazawa N, Tasaka T, Wada J, Yamasaki A, Kitaura Y, Sozaki M, Tanaka M, Onishi H, Morisaki T, et al. Intratumoral CD8(+) T/FOXP3 (+) cell ratio is a predictive marker for survival in patients with colorectal cancer. Cancer Immunol Immunother. 2010;59(5):653-61. 
39. Miyashita M, Sasano H, Tamaki K, Hirakawa H, Takahashi Y, Nakagawa S, Watanabe G, Tada H, Suzuki A, Ohuchi N, et al. Prognostic significance of tumor-infiltrating CD8+ and FOXP3+ lymphocytes in residual tumors and alterations in these parameters after neoadjuvant chemotherapy in triplenegative breast cancer: a retrospective multicenter study. Breast Cancer Res. 2015;17:124.

40. Nasman A, Romanitan M, Nordfors C, Grun N, Johansson H, Hammarstedt L, Marklund L, Munck-Wikland E, Dalianis T, Ramqvist T. Tumor infiltrating CD8+ and Foxp3+ lymphocytes correlate to clinical outcome and human papillomavirus (HPV) status in tonsillar cancer. PLoS One. 2012;7(6):e38711.

41. Li J, Wang J, Chen R, Bai Y, Lu X. The prognostic value of tumor-infiltrating T lymphocytes in ovarian cancer. Oncotarget. 2017;8(9):15621-31.

42. Boxberg M, Leising L, Steiger K, Jesinghaus M, Alkhamas A, Mielke M, Pfarr N, Gotz C, Wolff KD, Weichert W, et al. Composition and clinical impact of the immunologic tumor microenvironment in Oral squamous cell carcinoma. J Immunol. 2019;202(1):278-91.

43. dos antos Pereira J, da Costa Miguel MC, Guedes Queiroz LM, da Silveira EJ. Analysis of CD8+ and CD4+ cells in oral squamous cell carcinoma and their association with lymph node metastasis and histologic grade of malignancy. Appl Immunohistochem Mol Morphol. 2014;22(3):200-5.

44. Huang Z, Su W, Han Z, Yin J, Zhang Y, Li X. Tumor metastasis in patients with non-small cell lung cancer is inversely correlated with the number of tumor-infiltrating CD8(+) T cells. Xi Bao Yu Fen Zi Mian Yi Xue Za Zhi. 2019; 35(3):266-70.

45. Kimura H, Matsui Y, Ishikawa A, Nakajima T, lizasa T. Randomized controlled phase III trial of adjuvant chemoimmunotherapy with activated cytotoxic T cells and dendritic cells from regional lymph nodes of patients with lung cancer. Cancer Immunol Immunother. 2018;67(8):1231-8.

46. Sato E, Olson SH, Ahn J, Bundy B, Nishikawa H, Qian F, Jungbluth AA, Frosina D, Gnjatic S, Ambrosone C, et al. Intraepithelial CD8+ tumorinfiltrating lymphocytes and a high $\mathrm{CD} 8+$ /regulatory $T$ cell ratio are associated with favorable prognosis in ovarian cancer. Proc Natl Acad Sci U S A. 2005;102(51):18538-43.

47. Diederichsen AC, Hjelmborg J, Christensen PB, Zeuthen J, Fenger C. Prognostic value of the $C D 4+/ C D 8+$ ratio of tumour infiltrating lymphocytes in colorectal cancer and HLA-DR expression on tumour cells. Cancer Immunol Immunother. 2003;52(7):423-8.

48. Piersma SJ, Jordanova ES, van Poelgeest MI, Kwappenberg KM, van der Hulst JM, Drijfhout JW, Melief CJ, Kenter GG, Fleuren GJ, Offringa R, et al. High number of intraepithelial CD8+ tumor-infiltrating lymphocytes is associated with the absence of lymph node metastases in patients with large early-stage cervical cancer. Cancer Res. 2007;67(1):354-61.

49. Krupar R, Hautmann MG, Pathak RR, Varier I, McLaren C, Gaag D, Hellerbrand C, Evert M, Laban S, Idel C, et al. Immunometabolic determinants of Chemoradiotherapy response and survival in head and neck squamous cell carcinoma. Am J Pathol. 2018;188(1):72-83.

50. Wolf GT, Chepeha DB, Bellile E, Nguyen A, Thomas D, McHugh J, University of Michigan H, Neck SP. Tumor infiltrating lymphocytes (TIL) and prognosis in oral cavity squamous carcinoma: a preliminary study. Oral Oncol. 2015; 51(1):90-5.

\section{Publisher's Note}

Springer Nature remains neutral with regard to jurisdictional claims in published maps and institutional affiliations.

Ready to submit your research? Choose BMC and benefit from:
- fast, convenient online submission
- thorough peer review by experienced researchers in your field
- rapid publication on acceptance
- support for research data, including large and complex data types
- gold Open Access which fosters wider collaboration and increased citations
- maximum visibility for your research: over 100M website views per year
At BMC, research is always in progress.
Learn more biomedcentral.com/submissions

